\title{
O processo formativo: história, memória e trajetória de egressos/as do curso de Licenciatura em Educação do Campo da Universidade Federal de Roraima (LEDUCARR/UFRR)
}

\author{
Consuelem da Silva Sarmento ${ }^{1}$, iD Sergio Luiz Lopes ${ }^{2}$ \\ ${ }^{1}$ Secretaria Municipal de Educação - SMEC. Rua Cecília Brasil, 1078, Centro. Boa Vista - RR. Brasil. ${ }^{2}$ Universidade Federal \\ de Roraima - UFRR.
}

Autor para correspondência/Author for correspondence: consuelem@hotmail.com

\begin{abstract}
RESUMO. Este estudo tem como objeto a trajetória formativa de egressos/as do curso de Licenciatura em Educação do Campo de Roraima da Universidade Federal de Roraima (LEDUCARR/URR). O objetivo central foi identificar os desafios da profissão docente sob a perspectiva desses sujeitos, a partir de sua experiência formativa no referido curso. A pesquisa adotou como instrumento para a coleta de dados a entrevista (com 16 egressos/as), baseada no método da história oral (Thompson, 1998). A análise, de caráter qualitativo, estruturou-se a partir das categorias: o percurso formativo e a profissão docente. As vozes dos/as egressos/as revelaram a importância da LEDUCARR como efetivação de políticas públicas para a formação, em nível superior, dos sujeitos do campo, o que se constituía um sonho para maioria dos/as respondentes da pesquisa. Além disso, expuseram as dificuldades encontradas para conseguirem uma vaga para atuar nas escolas do campo. Para maioria dos/as entrevistados/as, a falta de reconhecimento do curso pelas entidades governamentais compromete incide sobre a oferta de vagas em seletivos e concursos públicos. Assim, o presente trabalho tem em vista a ampliação do debate sobre as propostas para a Educação do Campo.
\end{abstract}

Palavras-chave: formação docente, políticas públicas, educação do campo, história oral. 


\title{
The formative process: history, memory and path of LEDUCARR/UFRR graduates
}

\begin{abstract}
The object of this study is the formative trajectory of graduates of the Degree Course in Rural Education at the Federal University of Roraima. The main objective was to identify the challenges of the teaching profession from the perspective of these subjects, based on their formative experience in that course. The research adopted as an instrument for data collection the interview (with 16 graduates), based on the oral history method (Thompson, 1998). The analysis, of a qualitative nature, was structured from the categories: the training path and the teaching profession. The voices of the graduates revealed the importance of this course as an implementation of public policies for the training, at a higher level, of field subjects, which was a dream for most of the survey respondents. In addition, they exposed the difficulties encountered in getting a place to work in rural schools. For most interviewees, the lack of recognition of the course by government entities affects the offer of places in selective and public examinations. Thus, this work aims to expand the debate on proposals for Rural Education.
\end{abstract}

Keywords: teacher training, public policies, rural education. 


\section{El proceso formativo: historia, memoria y trayectoria de los ex alumnos del Curso de Licenciatura en Educación Rural de la Universidad Federal de Roraima (LEDUCARR/UFRR)}

RESUMEN. El objeto de este estudio es la trayectoria formativa de los egresados de la Licenciatura en Educación en el Campo de Roraima de la Universidad Federal de Roraima (LEDUCARR/UFRR). El objetivo principal fue identificar los desafíos de la profesión docente desde la perspectiva de estos sujetos, a partir de su experiencia formativa en dicho curso. La investigación adoptó como instrumento de recolección de datos la entrevista (con 16 egresados), basada en el método de historia oral (Thompson, 1998). El análisis, de carácter cualitativo, se estructuró a partir de las categorías: trayectoria formativa y profesión docente. Las voces de los egresados revelaron la importancia de LEDUCARR como una implementación de políticas públicas para la formación, a un nivel superior, de las asignaturas de campo, lo que era un sueño para la mayoría de los encuestados. Además, expusieron las dificultades encontradas para conseguir un lugar para trabajar en las escuelas rurales. Para la mayoría de los entrevistados, la falta de reconocimiento del curso por parte de las entidades gubernamentales afecta la oferta de plazas en exámenes selectivos y públicos. Así, este trabajo tiene como objetivo ampliar el debate sobre propuestas de Educación Rural.

Palabras clave: formación docente, políticas públicas, educación rural, historia oral. 


\section{Introdução}

O presente trabalho apresenta uma discussão sobre a história, a memória e as trajetórias de jovens egressos/as da primeira turma do curso de Licenciatura em Educação do Campo de Roraima (LEDUCARR) da Universidade Federal de Roraima (UFRR).

O interesse pelo tema se justifica pela importância de conhecer e registrar o processo formativo dos/as egressos/as da LEDUCARR e, principalmente, destacar o espaço e o contexto da sua própria história: a de serem moradores/as e educadores/as do campo. Justifica-se, também, pela importância de colocar em evidência a LEDUCARR como uma política pública, resultado das lutas dos movimentos sociais do campo, pois a educação para a população campesina sempre foi tratada como política compensatória, desprovida de ações concretas que visassem a um ensino adequado à realidade das escolas para o campo.

É um estudo que resulta de meu envolvimento com a educação do campo em Roraima, sobretudo na LEDUCARR, quando atuei como bolsista do Programa de bolsa Permanência (PANES/UFRR), no período de 2011 a 2014. E, posteriormente, no período de 2014 a 2016, quando desenvolvi atividades junto aos bolsistas de graduação do Programa Institucional de Bolsa de Iniciação à Docência para a Diversidade

(PIBID

Diversidade/LEDUCARR), na condição de professora Supervisora.

Essas ações possibilitaram maior aproximação com a realidade das escolas do campo, onde se promovia uma educação ancorada no envolvimento entre seus sujeitos, alunos/as e professores/as, a partir de temas específicos do campo, favorecendo ao/à educador/a do campo uma trajetória de formação diferenciada.

Diante do interesse anunciado e das contribuições supracitadas, propus-me a realizar, durante o Mestrado em Educação (2016 a 2018), uma pesquisa cujo principal objetivo foi compreender: os desafios da profissão docente enfrentados por egressos/as do LEDUCARR/UFRR. Essa pesquisa foi norteada pelas seguintes questões: qual a trajetória profissional dos/as egressos/as do referido curso? Que desafios estão postos para docentes multidisciplinares formados/as em tal curso? Os resultados obtidos nessa pesquisa estão sintetizados neste artigo.

Para iniciarmos, faremos um breve histórico dos primeiros passos para a construção da LEDUCARR na UFRR. 
A gênese da LEDUCARR na UFRR

O curso de Licenciatura em Educação do Campo de Roraima (LEDUCARR) é resultado do Edital de convocação $n^{0}$ 09, de 29 de abril 2009, do Programa de Apoio à Formação Superior em Licenciatura em Educação do Campo (PROCAMPO), por iniciativa do Ministério da Educação (MEC), por intermédio da Secretaria de Educação Continuada, Alfabetização, Diversidade (SECAD), com apoio da Secretaria de Educação Superior (SESU) e execução financeira do Fundo Nacional de Desenvolvimento da Educação (FNDE).

Após a aprovação pelo MEC, o projeto foi submetido à aprovação nas instâncias deliberativas da universidade, a saber: Câmara do Curso de Pedagogia, Conselho de Centro de Educação (CEDUC), Câmara de Graduação, Conselho de Ensino Pesquisa e Extensão (CEPE) e o Conselho Universitário (CUNI). Realizados os trâmites, foi publicado o primeiro edital para o vestibular do Curso de Licenciatura em Educação do Campo de Roraima LEDUCARR.

Quanto ao perfil do/a ingressante, o edital destinou vagas especificamente para educadores/as que atuavam na área de educação básica do campo, da rede pública, em escola de qualquer munícipio de Roraima (exceto os que atuavam na capital do município de Boa Vista), e que possuíam nível médio completo.

Tendo conhecimento de que as vagas haviam sido destinadas apenas para professores/as que não possuíam graduação, representantes dos movimentos sociais, através da Federação dos Trabalhadores e Trabalhadoras na Agricultura do Estado de Roraima (FETAG/RR), entraram com pedido de impugnação do edital. Seus argumentos foram cabíveis ao questionarem o edital quanto a ofertas de vagas destinadas apenas a uma pequena parcela dos sujeitos do campo. Logo, requereram que as vagas também se estendessem a todos/as os/as moradores/as das comunidades rurais dos municípios de Roraima, portadores/as de certificado de conclusão do ensino médio completo.

Esse fato remete-nos aos argumentos de Arroyo (1999), quanto à participação dos Movimentos Sociais nas tomadas de decisões. Segundo o autor,

A Educação do Campo não é
questionada pela educação das
cidades, nem por uma nova moda
pedagógica, nem por uma nova
política pública, nem sequer pela
modernização produtiva do
agronegócio, nem pela moderna
burguesia agrária, mas pelos
Movimentos Sociais, pelos povos do
campo organizados (Arroyo, 1999, p.
9).

A Educação do Campo não é questionada pela educação das cidades, nem por uma nova moda pedagógica, nem por uma nova política pública, nem sequer pela modernização produtiva do agronegócio, nem pela moderna burguesia agrária, mas pelos 9). 
Com isso após reivindicações, as vagas, além de serem destinadas aos/às professores/as que atuavam em escolas do campo e não possuíam o ensino superior, passou a atender a jovens e adultos/as que participavam de ações educativas nas diversas organizações, movimentos sociais e rurais; pessoas que atuavam como educadoras ou coordenadoras de escolarização básica em comunidades rurais; e trabalhadores/as rurais. Assim, a forma de ingresso foi publicada através da Comissão Permanente de Vestibular (CPV) da UFRR, com oferta de 60 vagas, sendo 30 vagas para a área de concentração em Ciências Humanas e Sociais e 30 para a área de concentração em Ciências da Natureza e Matemática, em período integral, na perspectiva da Pedagogia da Alternância.

A respeito da Pedagogia da Alternância, esta consistia na articulação entre Tempo Universidade (TU), nos meses de janeiro e fevereiro; julho e agosto, e Tempo Comunidade (TC), nos meses de março, abril e maio; setembro, outubro e novembro. No período do TU, os/as alunos/as permanecem no espaço da universidade em regime de internato espaço de formação. No TC, os/as alunos/as retornam às suas propriedades familiares, comunidades ou ainda aos assentamentos, para colocarem em prática os conhecimentos adquiridos e que foram objetos de estudos no TU.

\section{Metodologia}

A pesquisa foi baseada no método da história oral (Thompson, 1998), como forma de reforçar e legitimar a identidade dos/as educadores/as do campo, pois, nos permite o registro de testemunhos de acontecimentos e vivências, ampliando as possibilidades de interpretação do passado. Esse método subsidia a pesquisa não apenas no sentido de fornecer o registro das memórias dos indivíduos, mas também, ao focalizar suas memórias pessoais, proporciona uma visão da trajetória do próprio grupo social.

O registro de tais memórias foi realizado por meio de entrevista, que seguiu as recomendações de Thompson (1998). Dessa forma, foi possível obter informações das dimensões básicas biológica, cultural e social - dos membros participantes desta pesquisa.

A pesquisa empírica foi dividida em três momentos: a elaboração do roteiro da entrevista (dividido em blocos temáticos), estabelecendo o cuidado necessário para evitar qualquer contexto de desconforto para os sujeitos da pesquisa; a aplicação da entrevista (com 16 egressos/as) nos municípios mapeados e, por fim, a transcrição e a análise dos dados, com o 
objetivo de entrelaçar as informações coletadas com os estudos e as leituras realizadas sobre a temática educação do campo.

Visando à preservação do anonimato dos/as participantes da pesquisa, atribuímos a codificação $\mathrm{R}$, que corresponde a "respondente", acrescida do número do/a participante, como, por exemplo, R-1, R-2, R-3 e, assim, sucessivamente.

A análise dos dados seguiu a abordagem qualitativa, que, segundo Minayo (2012, p. 622), tem uma matériaprima formada por:

... conjunto de substantivos cujos sentidos se complementam: experiência, vivência, senso comum e ação. E o movimento que informa qualquer abordagem ou análise se baseia em três verbos: compreender, interpretar e dialetizar.

Neste artigo, selecionou-se como bloco temático de análise o percurso formativo dos/as egressos/as. Isto é, pretende-se a partir daí observar como encararam o momento de formação inicial; como escolheram a área de atuação; qual o significado, para eles/as, de ingressar no ensino superior em uma universidade pública; verificar se o/a entrevistado/a terminou o curso no período proposto pela instituição e, por fim, entender como ocorreu o processo formativo em um curso com uma metodologia bastante diferente dos cursos convencionais de licenciatura.

\section{O percurso formativo}

Esse bloco temático teve como foco compreender os fatores que contribuíram para que os/as participantes da pesquisa se inscrevessem em um curso de licenciatura direcionada para a Educação do Campo, em uma universidade pública. Ao responderem a tal questão, os/as participantes revelaram aspectos sobre 0 contexto no qual estão inseridos, com realidades diversas e complexas: condição socioeconômica desfavorável, escolarização precária (muitas vezes), influência de um discurso falso de meritocracia.

Os/as entrevistados/as usam diversas explicações quando questionados sobre o porquê da escolha em cursar uma licenciatura voltada para o campo. Porém, todos/as revelam a importância de, como forma de resistência às adversidades, estar inserido/a em uma instituição de ensino superior com o propósito de adquirir um ofício - à docência.

Nota-se, em suas subjetividades, que se trata de sujeitos cujas oportunidades de melhorias de vida são poucas, portanto abraçam as chances que surgem. 
A falta de oportunidades de cursos, porque aqui em Caroebe não tinha curso superior, foi a primeira oportunidade que veio para o morador do município, fiz minha inscrição e passei no vestibular (R-1). Quando fiquei sabendo do curso, vi que era uma grande oportunidade de melhorar de condições, tanto em questões de estudos como financeira (R-10).

É importante notar, nas duas falas, que 0 ingresso no ensino superior representou uma oportunidade ímpar. Observa-se também a dificuldade de ingressar em uma universidade devido à distância e o pouco comprometimento do país com as áreas do campo.

Os/as participantes expressam que o ingresso em uma instituição de nível superior representou a realização de um sonho, como, por exemplo, R-2 afirma que tinha o

... sonho de fazer um curso Universidade Federal de Roraima e aí como já conhecia um pouquinho sobre o curso com a pedagogia da alternância, pensei quero fazer um curso igual o meu ex-marido fez, até abandonei o curso de geografia para fazer, mas esperei passar primeiro no vestibular.

A fala de R-11 também apresenta essa mesma perspectiva: "Fiz o vestibular e passei. Foi a realização de um sonho" (R11).

Percebe-se também, na fala de R2, uma deliberação em sua escolha por um curso pautado na Pedagogia da
Alternância, já que tinha conhecimento da modalidade, na qual a Educação do Campo está estruturada.

Observa-se que a expressão “oportunidade" está presente em todos os relatos: "Foi uma oportunidade que apareceu, então arrisquei sem ter certeza se ia conseguir ou não" (R-13). Ou seja, ainda que não se esteja falando da conquista em concluir um curso superior, nota-se, implicitamente, a satisfação em estar na universidade e ter alcançado um sonho, estar em um curso superior.

É comum, para quem vive no campo, se deparar com momentos de inseguranças em face das dificuldades de acesso às novas tecnologias e demais políticas públicas, e, com isso, deixa-se o campo e migra-se para a capital, em busca de melhores condições de vida. Compreendese, portanto, a partir das falas, que o campo é um ambiente pouco atrativo devido à falta de condições adequadas para realização de sonhos.

Essa escassez de recursos é revelada na fala de R-5: "Sempre quis fazer uma faculdade, mas desprovia de recursos financeiros. Como o curso LEDUCARR era totalmente gratuito, pois, a universidade custeava a hospedagem, alimentação e transporte, vi que seria a oportunidade única para cursar uma graduação". 
A realidade de $\mathrm{R}-5$ corresponde à de grande parte das pessoas que vivem no campo, o que nos ajuda a compreender a relação entre três expressões-chave nas falas dos/as respondentes, a saber: o sonho, a realidade e o ensino superior gratuito. Vê-se, nitidamente, um depoimento que denuncia as poucas condições do espaço campo. Porém, mesmo com dificuldades, o sonho perdurou e essa pessoa conseguiu concluir o ensino superior. Certamente a resposta ajuda a entender a importância do respeito aos povos do campo, a começar pelos próprios sistemas educacionais.

Outra fala revela o envolvimento coletivo para busca de melhorias para o campo:

Fazia parte do sindicato e já trabalhava na luta por uma educação do campo e quando surgiu essa oportunidade, imaginávamos que não iriamos conseguir por sermos jovens e a princípio as vagas seriam para atender somente os professores que não possuíam graduação. Quando abriu a oportunidade para os filhos de agricultores, fiz minha inscrição para fazer o vestibular da LEDUCARR, (R-14).

Aqui aparece uma proposição interessante, 0 sujeito que tem engajamento político e reflexivo consegue entender melhor o papel da escola e do estudo em sua comunidade, o que o encorajou a fazer o vestibular e ingressar no ensino superior. E novamente a expressão "oportunidade" é mencionada, por se tratar de algo raro dentro do contexto em que esses sujeitos estão inseridos.

Nesse sentido, ressaltamos a importância das instituições públicas de ensino superior no campo - e para o campo - como caminho para a criação oportunidades e desenvolvimento do campo. Delors (2012) elenca as contribuições que a universidade pode oferecer. Segundo o autor, essa instituição serve:

- como local de ciência, como fonte de conhecimentos, com vista à pesquisa teórica ou aplicada, ou à formação de professores;

- como meio de adquirir qualificações profissionais, conciliando ao mais alto nível, o saber e o saber-fazer, em cursos e conteúdos constantemente adaptados às necessidades da economia;

- como recinto privilegiado da educação ao longo de toda a vida, abrindo as portas aos adultos que desejem retomar seus estudos, adaptar e enriquecer os seus conhecimentos, ou satisfazer seu gosto de aprender em qualquer domínio da vida cultural;

- como parceiro privilegiado de uma cooperação internacional, permitindo o intercâmbio de professores e alunos e facilitando, graças a matérias de caráter internacional, a difusão do que de melhor se faz no campo do ensino (Delors, 2012, p. 24, grifo nosso).

Observe-se que o entendimento do autor ratifica a fala dos/as respondentes, especificamente quando atribuem à 
universidade a expressão "oportunidade", ou seja, um abrir de "portas", como menciona Delors (no grifo da citação).

Outra questão que nos chama a atenção é que o curso na modalidade de alternância possibilitou estudar em tempo de férias, como revela a fala a seguir: “... a modalidade do curso, por ser um curso de alternância, facilitou bastante, porque conseguir conciliar o trabalho, pois, se fosse um curso regular eu não teria condições de ter feito um curso na UFRR" (R-9).

É importante frisar que os sujeitos do campo, por residirem distante dos grandes centros urbanos, acabam sendo prejudicados quando se trata da formação profissional, porque nem sempre os possuem condições socioeconômicas e orientações para acompanharem a logística do ensino superior convencional.

De acordo com Silva (2014, p. 125126):

A Pedagogia da Alternância consiste em promover uma formação escolar em que o aprendiz vivencia períodos de tempos que se alternam entre a vivência na escola e na família, buscando, de modo a conciliar o aprendizado na escola com o aprendizado da vida. Essa experiência não fortalece apenas a relação teórica e prática, mas também auxilia no desenvolvimento de prática ecologicamente viáveis na relação homem e natureza, não permitindo que o jovem se desligue do seu ambiente, ao tempo em que se valoriza o tempo escola e o tempo comunidade.

Parte dos discursos acima caminha na mesma direção, o ingresso na universidade como forma de ampliar o universo de oportunidades e, como, afirma R-12, “... adquirir novos conhecimentos”. No entanto, as escolas do campo com as suas dificuldades nem sempre despertam nos/as jovem o interesse pela permanência em sala de aula, além disso, por se tratar de jovens que vivem trabalhando, muitas vezes com os seus pais, esses/as jovens têm dificuldades de concluir seus estudos no ensino básico, de modo que chegar até a universidade parece ser para eles/as um sonho muito distante.

Assim, conforme Caldart (2004) as escolas do campo devem ser vistas como espaços em movimento: elas têm vida, têm troca de saberes e história. Para a autora, a Educação do Campo deve estar vinculada à luta dos povos do campo por melhorias de suas condições de vida.

É notório, pelos depoimentos, que os povos do campo enfrentam uma realidade permeada de dificuldades de diversos tipos, decorrentes das desigualdades sociais, que caracterizam não apenas o estado de Roraima, mas todo o país. Frente a essa realidade, muitos/as, portanto, acabam aproveitando a única (talvez) 
oportunidade que lhes é oferecida, é o caso dos/as respondentes de nossa pesquisa.

\section{Do campo à sala de aula: sonho ou utopia}

Compreendida a motivação para o ingresso em um curso superior, importa saber o quanto se identificaram com esse curso, ou seja, após abraçarem tal oportunidade, será que fizeram o que gostam?

Diante dessa indagação, os/as respondentes afirmam que gostavam do curso e reiteram que se tratava de realização de um sonho. Em outras palavras, pode-se notar o quanto o ingresso em um curso superior é capaz de favorecer a um sujeito (especialmente, aqui, o sujeito do campo) a realização de um sonho, o qual seria difícil realizar sem o apoio do setor público.

Quanto à questão levantada, o depoimento de R-2 nos chama a atenção:

... gostava muito. Apesar de muitas vezes deixar transparecer que o curso foi mais por questões de status, durante o período de formação fui percebendo que o curso tinha tudo a ver com minha história de vida. Os debates em sala de aula, foram aos poucos me fazendo conhecedora dos motivos pelos quais fiquei impossibilitada de estudar durante quatro anos após concluir a quarta série. Recordo-me que chorava por não poder ir à escola devido à falta de escola na vicinal. E depois quando passamos a frequentar a escola na sede do município éramos tratados com os rurais e então no LEDUCARR foi que fui entender o que estava por trás de tudo que vivi. Me identifiquei muito com o curso, gostei muito (R-2).

O depoimento é amplo e percebemos três pontos básicos: o prazer em estar na universidade, a percepção de que o curso dialogava com sua própria realidade de vida e a descoberta das razões que a impossibilitaram de estudar, em um determinado momento de sua vida. Ou seja, o curso despertou-lhe a consciência e a reflexão sobre sua própria realidade.

O despertar pode significar curiosidade e criticidade, como assinala Freire (2013, p. 33):

A curiosidade como inquietação indagadora, como inclinação ao desvelamento de algo, como pergunta verbalizada ou não, como procura de esclarecimento, como sinal de atenção que sugere alerta faz parte integrante do fenômeno vital. Não haveria criatividade sem a curiosidade que nos move e que nos põe pacientemente impacientes diante do mundo que não fizemos, acrescentando a ele algo que fazemos.

Nessa perspectiva, a autonomia e a liberdade são elementos-chave na educação, tanto para o docente como para o aluno. Pensar em ensino sem reflexão é cair nas armadilhas do fatalismo tradicional que trata o sujeito-aluno como uma folha em branco, na qual são depositadas, mecanicamente, informações. 
Ao contrário, a educação - e aqui nos referimos, especificamente à Educação do Campo - promove transformações sociais quando discute e é pautada em: cidadania, liberdade, autonomia e identidade do povo do campo.

Sabemos que muitos desses sujeitos tiveram suas vidas laminadas pelos contextos aos quais estiveram/estão submetidos/as. Enfrentaram situações que, de um lado, os/as levaram a se sentirem completamente perdidos/as e, de outro, estimularam neles/as a esperança e o objetivo de ser "alguém" na vida, como, por exemplo, voltar para a sua comunidade e desenvolver a atividade docente.

Esta breve análise nos possibilita inferir que os/as respondentes, egressos/as do curso LEDCARR/RR: a) sentiram grande satisfação em fazer um curso superior, possivelmente motivados/as pelo entendimento de que o curso possibilita a garantia do seu futuro profissional na comunidade; b) se identificam com o curso, uma vez que possibilitou a reflexão sobre sua realidade e, assim, a aquisição de mais autonomia e independência.

\section{Considerações finais}

Sabemos que o histórico da educação do campo é marcado por lutas dos movimentos sociais para minimizar o problema de exclusão social. Embora tenha sido uma grande conquista, a Educação do Campo ainda enfrenta grandes desafios, e um deles é tornar possível a inserção dos/as egressos/as da LEDUCARR/RR na docência das escolas do campo existentes em Roraima. Nessa perspectiva, ao analisarmos as falas dos/as egressos/as da LEDUCARR, ficou evidente que curso tem papel primordial na formação inicial dos/as educadores/as do campo, como dito por um dos respondentes o curso trás "a valorização do homem do campo como sujeito de ação" (R-2).

A pesquisa permitiu verificar que os egressos após a formação encontram dificuldades para a inserção na docência, assim como também as encontraram durante o período de formação. Em algumas falas foi pontuada a falta de logística durante os Encontros de Formação Tempo Universidade e Tempo Comunidade.

... deixava muito a desejar, fugia do que era a proposta, porque era para ter um acompanhamento durante o Tempo Comunidade para colocarmos em prática os assuntos estudados durante o Tempo Universidade e isso poucas vezes acontecia ( $\mathrm{R}-4)$.

... o Tempo Comunidade nunca saía como era planejado, mas, de qualquer forma sempre conseguíamos adquirir novos conhecimentos. Mesmo, com a falha no planejamento no final dava certo (R-12). 
A falta do reconhecimento do curso pelas municipalidades e pelo estado, no sentido de ofertar vagas que contemplem a formação dos/as egressos/as, foi uma das questões mais presentes na fala dos respondentes, o que para eles explica o fato de muitos ainda não estarem atuando.

Apesar de terem se identificado com o curso, houve, entre os/as egressos/as, uma inquietação quanto ao curto espaço de formação para habilitação em quatro áreas de conhecimento. Além disso, e manifestaram descontentamento com a organização dos espaços de formação do Tempo Comunidade na proposta da Pedagogia da Alternância, que não ocorriam. As falas de R-3 e R-4 expressam essa inquietação:

Nem sempre a alternância atendia o que esperávamos, às vezes o professor resumia tanto um assunto devido ao pouco tempo, às vezes não dava tempo para estudar todos os assuntos, devido ao acúmulo dos assuntos, como estudávamos em tempo integral se tornava exaustivo (R-3).

... deixava muito a desejar, fugia do que era a proposta, porque era para ter um acompanhamento durante o Tempo Comunidade para colocarmos em prática os assuntos estudados durante o Tempo Universidade e isso poucas vezes acontecia (R-4).

Os dados obtidos nesta pesquisa indicam uma série de desafios enfrentados pelos/as egressos/as da primeira turma da LEDUCARR. Um desses desafios foi ter de se adaptar a carência de recursos: “... no interior a gente não tinha acesso a internet. A falta de acesso a pesquisas na biblioteca dificultava muito" (R-14).

É importante mencionar que nenhum/a dos/as respondentes da pesquisa exercia a profissão docente antes do curso, e se não fosse a reivindicação dos Movimentos Sociais, através da FETAG/RR, para que o curso também fosse ofertado aos/às moradores/as das comunidades rurais dos municípios de Roraima, portadores/as de certificado de conclusão do ensino médio completo, certamente os/as participantes da pesquisa não teriam realizado seu sonho de ingressar em uma universidade.

Sobre a atuação docente, apenas 6 dentre 16 respondentes estão atuando na sala de aula, alguns/algumas iniciaram a docência já no $4^{\circ}$ semestre do curso. Os/as demais respondentes apenas tiveram contato com sala de aula durante os estágios obrigatórios do curso e durante o PIBID/DIVERSIDADE - sendo que de 16 respondentes apenas 3 não foram bolsistas do referido programa. Para os/as respondentes, o PIBID é de grande relevância para alunos de graduação, faz com que tenha a vivência da prática docente. 


\section{Referências}

Arroyo, M. G. (1999). Educação básica e movimentos sociais. Articulação Nacional por uma Educação Básica do Campo. Brasília, DF: Coleção Por uma educação básica do campo, v. 2.

Caldart, R. S. (2000). Pedagogia do Movimento Sem Terra: escola é mais do que escola. Petrópolis: Editora Vozes.

Caldart, R. S. (2004). Por uma educação do campo: traços de uma identidade em construção. In Arroyo, M. G., Caldart, R. S., \& Molina, M. C. (Orgs.). Por uma Educação do Campo (s./p.). Petrópolis: Vozes.

Delors, J. (2012). Prefácio. Delors, J. et al. Educação um tesouro a descobrir Relatório para a Unesco da Comissão Internacional sobre Educação para o Século XXI. 7. ed. São Paulo: Cortez, 2012.

Edital de convocação $n^{\circ} 09$ (29 de abril de 2009). Recuperado de: http://portal.mec.gov.br/dmdocuments/edit al_procampo_20092.pdf.

Freire, P. (2013). Pedagogia da Autonomia: saberes necessários à prática educativa. 46. ed. São Paulo: Paz e Terra.

Fragoso, M. B. (2000). Pedagogia do Movimento Sem Terra: escola é mais do que escola (resenha). Rev. Bras. Educ. (15). $\quad$ https://doi.org/10.1590/S141324782000000300011

Minayo, M. C. S. (2012). Análise qualitativa: teoria, passos e fidedignidade. Ciência \& Saúde Coletiva, 17(3), 621-626. https://doi.org/10.1590/S1413$\underline{81232012000300007}$
Silva, A. M. (2014). Educação do Campo: uma breve (re)construção Epistemológica. In Lima, E. S. L., \& Silva, A, M. (Orgs.). Diálogos sobre Educação do Campo (s./p). 2. ed. Teresinha: EDUFPI.

Thompson, P. (1998). A voz do passado: História Oral. 2. edição. São Paulo: Paz e Terra.

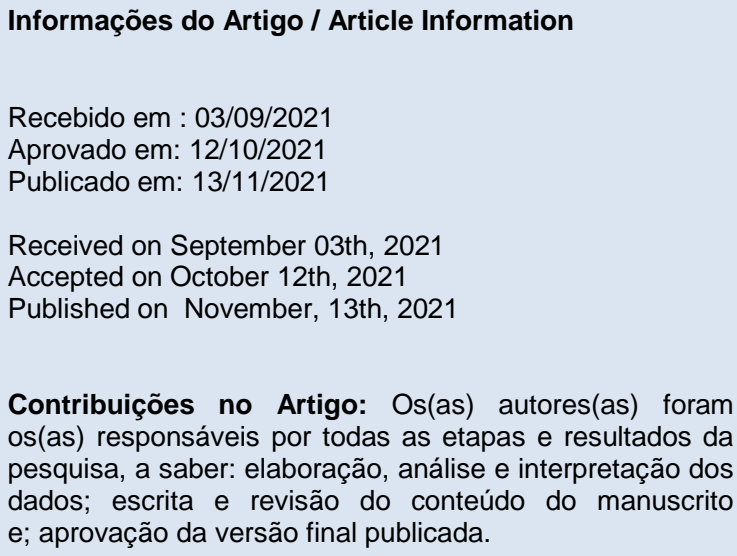

Contribuições no Artigo: Os(as) autores(as) foram os(as) responsáveis por todas as etapas e resultados da pesquisa, a saber: elaboração, análise e interpretação dos dados; escrita e revisão do conteúdo do manuscrito e; aprovação da versão final publicada.

Author Contributions: The author were responsible for the designing, delineating, analyzing and interpreting the data, production of the manuscript, critical revision of the content and approval of the final version published.

Conflitos de Interesse: Os(as) autores(as) declararam não haver nenhum conflito de interesse referente a este artigo.

Conflict of Interest: None reported.

Avaliação do artigo

Artigo avaliado por pares.

Article Peer Review

Double review.

Agência de Fomento

Não tem.

Funding

No funding.

Como citar este artigo / How to cite this article 
APA

Sarmento, C. S., \& Lopes, S. L. (2021). O processo formativo: história, memória e trajetória de egressos/as do curso de Licenciatura em Educação do Campo da Universidade Federal de Roraima (LEDUCARR/UFRR). Rev. Bras. Educ. Camp., 6, e13004. http://dx.doi.org/10.20873/uft.rbec.e13004

\section{ABNT}

SARMENTO, C. S.; LOPES, S. L. O processo formativo: história, memória e trajetória de egressos/as do curso de Licenciatura em Educação do Campo da Universidade Federal de Roraima (LEDUCARR/UFRR). Rev. Bras. Educ. Camp., Tocantinópolis, v. 6, e13004, 2021. http://dx.doi.org/10.20873/uft.rbec.e13004 